\title{
Economia popular solidária e o seu programa social
}

\author{
Solidarity economy and its social program
}

Caroline Goerck*

\begin{abstract}
Resumo
Este artigo objetiva demonstrar os resultados de uma pesquisa que averiguou a contribuição do extinto Programa de Economia Solidária em Desenvolvimento para a viabilidade das experiências coletivas de geração de trabalho e renda no Rio Grande do Sul. Este programa social foi criado em 2003, pelo governo federal, com vistas a fortalecer os empreendimentos de geração de trabalho e renda, juntamente com a Secretaria de Economia Solidária - Senaes - que foi extinta em 2016. A operacionalização do mencionado Programa ocorreu por meio de parcerias estabelecidas entre o estado (Secretaria Nacional de Economia Solidária - Senaes), instituições da sociedade civil, outros setores governamentais e incubadoras universitárias. Partiu-se do pressuposto que o Programa se constituiu como elemento potencializador de geração de renda para os sujeitos que estavam à margem do mercado formal de trabalho, especialmente os menos qualificados, mas que, contraditoriamente, também se configurou em mecanismos de regulação do capitalismo, para atenuar os conflitos de classe e reproduzir o sistema. Constatou-se, que, tanto o estado, por meio do Programa, em parceria com instituições da sociedade civil, outros setores governamentais, incluindo as incubadoras universitárias podiam, mesmo que de forma incipiente, potencialmente viabilizar as experiências de Economia Popular Solidária.
\end{abstract}

Palavras-chave: Geração de Trabalho e Renda. Instituições de Apoio. Viabilidade. Programa de Economia Solidária.

\begin{abstract}
This article aims to demonstrate the results of a research that investigated the contribution of the extinct Program of Solidary Economy in Development to the viability of collective experiences of generation of work and income in Rio Grande do Sul. This social program was created in 2003, by the federal government, with a view to strengthening work and income generation ventures, together with the Secretariat for Solidarity Economy - Senaes - which was extinguished in 2016. The operationalization of the mentioned Program took place through partnerships established between the State (National Secretariat for Solidarity Economy - Senaes), civil society institutions, other government sectors and university incubators. It was assumed that the Program was constituted as an element that promotes income generation for subjects who were on the margins of the formal labor market, especially the less qualified, but which, contradictorily, was also configured in capitalism regulation mechanisms, to mitigate class conflicts and reproduce the system. It was found that, both the State, through the Program, in partnership with civil society institutions, other government sectors, including university incubators, could, even if in an incipient way, potentially enable the experiences of Popular Solidarity Economy.
\end{abstract}

Keywords: Work and income generation. Support Institutions. Viability. Solidarity Economy Program.

\footnotetext{
* Graduada em Serviço Social pela Unisc (2003), Mestre (2006), Doutora (2009) e Pós-doutora (2011) em Serviço Social pelo Programa de Pós-Graduação da Pontifícia Universidade Católica do Rio Grande do Sul. É professora do Curso de Serviço Social Bacharelado da Universidade Federal de Santa Maria e coordenadora do NEPEQSPS.
} 


\section{Introdução}

Este artigo é resultado de uma pesquisa desenvolvida que buscou investigar a possível contribuição do extinto Programa de Economia Solidária em Desenvolvimento, para a viabilidade econômica dos empreendimentos de Economia Popular Solidária no Rio Grande do Sul, desenvolvido pela Secretaria Nacional Solidária - Senaes.

O governo federal com o objetivo de fortalecer, promover e viabilizar economicamente empreendimentos de geração de trabalho e renda; e ainda absorver os trabalhadores não incluídos no mercado formal de trabalho criou em 2003 no Ministério do Trabalho e Emprego - MTE, a Secretaria Nacional Solidária -Senae, tornando a Economia Popular Solidária integrante da agenda pública brasileira.

Durante o governo do ex-presidente Lula, a Economia Popular Solidária recebeu amplo incentivo do governo federal, promovendo diversas ações que visavam apoiar os empreendimentos coletivos em seus territórios, através de programas criados a partir da própria secretaria ou se aliando aos já existentes de outras secretarias de forma transversal. A partir do início do segundo governo Dilma, a Senaes sofreu com a diminuição de investimento financeiro, sendo que com o golpe parlamentar em abril de 2016 e com a mudança do governo, imposta pelo impeachment, ocasionou a destituição da gestão desta secretaria.

O processo de assessoria e incubação que consistia em um dos objetivos das Senaes, teve como perspectiva possibilitar que os trabalhadores destes empreendimentos coletivos pudessem usufruir de melhores condições de vida e de trabalho, pois o labor é elemento central da organização de uma sociedade. $O$ trabalho que é realizado pelos sujeitos de modo geral comumente não é constituído pela sua autorrealização, pois frente à reestruturação do capitalismo, criou-se uma massa de trabalhadores sobrantes, que acirrou a precariedade das condições e relações de trabalho (LEBOUTTE, 2003). Com esta realidade no final do século XX foram criadas experiências com grupos associativistas e cooperativistas no Brasil e no mundo, como fruto das manifestações de desigualdade da questão social.

A Economia Popular Solidária expressa formas associativistas e cooperativistas de produção, de prestação de serviços, de comercialização e de consumo (BRASIL, 2011a). Podese salientar, também, que o trabalho realizado nestes empreendimentos populares e coletivos além de gerar renda em algumas experiências, possivelmente, agrega princípios que 
potencializam o processo de trabalho e, normalmente, não são proporcionados pelos demais empreendimentos inseridos no sistema.

Estes princípios originados pelos Precursores do Cooperativismo estão respaldados na solidariedade, na democracia, na aproximação da autogestão, na participação, na posse coletiva dos meios de produção, no processo de rotatividade de funções e na divisão de renda entre os associados que, de forma democrática, deveriam definir estratégias de repartição, de cooperação na produção e no trabalho, e ainda de compromisso com o desenvolvimento humano e de preservação do meio ambiente.

Mediante a operacionalização desses princípios nos processos de produção e gestão, os sujeitos detêm a possibilidade de elaborar as suas próprias regras no cotidiano de trabalho, bem como alcançar um novo patamar de politização e participação social (SINGER, 2000). Quando se percebe que trabalhadores inseridos em empreendimentos coletivos, entretanto, não desenvolvem suas atividades de modo que tenham entendimento sobre os princípios do cooperativismo, ou, ainda, mesmo que estes trabalhadores desenvolvam suas atividades conforme estes princípios, estas experiências também se configuram como estratégias do próprio capital para atenuar os conflitos de classe, mantendo assim o capitalismo.

Frente a isto, não se compreende a Economia Popular Solidária, nem com excesso de otimismo, e, nem com excesso de pessimismo, pois opta pelo realismo analítico, respaldado no método dialético-crítico. Portanto, estes empreendimentos não substituem o sistema capitalista, pois os mesmos estão inclusos neste modo de produção e tentam se inserir no seu ciclo de reprodução. Estes empreendimentos podem também caracterizar a precarização do trabalho coletivo, uma vez que estes sujeitos, geralmente, não possuem acesso aos direitos trabalhistas.

Em relação à compreensão da viabilidade analisada - que corresponde aquilo que é viável, possível, realizável, exequível -, é compreendida neste artigo como a forma dos empreendimentos de Economia Popular Solidária se manterem no sistema, de modo que por intermédio das atividades desenvolvidas pelos sujeitos nas experiências, estes possam pagar suas despesas e também obter sobra, que por sua vez, gerará a renda dos trabalhadores. Esta compreensão vinculada ao aspecto econômico do processo de viabilidade, corresponde também à orientação que havia da Senaes, em relação a estes empreendimentos coletivos. Esta percepção estava relacionada com o fato de que num primeiro momento, estas experiências se constituem como uma das formas alternativas de geração de renda aos 
sujeitos que estão comumente em situação de vulnerabilidade social.

\section{Caminhos Metodológicos}

No Rio Grande do Sul, delimitação deste estudo, investigações sobre a contribuição do Programa de Economia Solidária à viabilidade econômica das experiências coletivas são importantes - tendo em vista a extinção da política pública e de seu programa social, pois, o mesmo ainda estava em fase de implantação e de implementação no Brasil. O problema concebido à pesquisa foi: como o Programa de Economia Solidária - por meio das instituições vinculadas ao referido Programa por intermédio da Senaes -, vem contribuindo para a viabilidade das experiências coletivas de geração de trabalho e renda no Rio Grande do Sul?

Este estudo foi realizado tendo como embasamento as categorias teórico-temáticas: Geração de Trabalho e Renda; Instituições de Apoio; Viabilidade e Programa de Economia Solidária. As categorias teórico-metodológicas e temáticas nortearam a pesquisa literária, as análises documentais, a coleta das informações e análise dos dados obtidos com os trabalhadores, com as experiências e instituições pesquisadas. $O$ enfoque qualitativo foi predominante neste estudo, embora tenha-se levado em consideração, também, os dados quantitativos (pois se compreende que os dados qualitativos e quantitativos se complementam).

O problema de pesquisa é complementado e constituído pelos seguintes questionamentos e interrogações norteadoras: Quais são as instituições que vêm assessorando as experiências de geração de trabalho e renda no Rio Grande do Sul, por meio do Programa de Economia Solidária por intermédio da Senaes? Quais são as experiências coletivas de geração de trabalho e renda, existentes no Rio Grande do Sul, que estão sendo assessoradas por meio de instituições vinculadas ao Programa de Economia Solidária por intermédio da Senaes? Quais são as características socioeconômicas dos sujeitos que integram as experiências de geração de trabalho e renda, existentes no Rio Grande do Sul, e que estão sendo assessoradas por meio das instituições vinculadas ao Programa de Economia Solidária por intermédio da Senaes? Quais são as características socioeconômicas das experiências coletivas de geração de trabalho e renda, existentes no Rio Grande do Sul, e que estão sendo assessoradas por meio das instituições vinculadas ao Programa de Economia Solidária por intermédio da Senaes? Como as instituições que vêm assessorando as experiências coletivas de geração de trabalho e renda no Rio Grande do Sul - por meio do 
Programa de Economia Solidária por intermédio da Senaes -, estão desenvolvendo os seus processos de incubação/assessoria? Como vem sendo implantado o Programa de Economia Solidária no Rio Grande do Sul? (ECONOMIA..., 2007).

Foi estabelecida a delimitação temporal do ano de 2003 (criação da Senaes) até 2009, portanto antes de sua extinção, para poder avaliar como este programa vinha sendo realizado no Rio Grande do Sul e perceber sua possível efetividade ou não. A coleta das informações ocorreu por meio da revisão literária sobre o tema e contato estabelecido com a Senaes, assim como pela análise dos seguintes documentos: Programa de Economia Solidária em Desenvolvimento, Mapeamento de Economia Solidária e ainda materiais pertencentes a 7 instituições vinculadas a Senaes ou ao Programa de Economia Solidária em Desenvolvimento, além de materiais pertencentes as 17 experiências coletivas. Destes empreendimentos, 14 estão sendo assessorados por instituições de apoio que possuíam vínculo com a Senaes, e 3 empreendimentos assessorados por instituições que já tiveram vínculo com o Programa de Economia Solidária em Desenvolvimento pela Senaes.

Também foram coletadas informações por meio da aplicação de um questionário respondido por 7 instituições, bem como também 2 formulários aplicados mediante a técnica de entrevista às lideranças (18) e demais trabalhadores (28) dos 17 empreendimentos pesquisados ${ }^{1}$ existentes nos meios urbanos em municípios do Rio Grande do Sul, totalizando 46 entrevistas desenvolvidas com os trabalhadores das experiências pesquisadas. Tanto as entrevistas e a escolha das experiências pesquisadas, como também a coleta nas instituições analisadas - 11 no total -, ocorreram por meio da amostra intencional.

Anteriormente à realização das entrevistas, bem como ao envio dos questionários às instituições foi apresentado aos participantes da pesquisa um Termo de Consentimento Livre e Esclarecido. Os dados quantitativos foram complementados pelas informações qualitativas - predominantes neste estudo -, e submetidos à análise de conteúdo (BARDIN, 2011).

Destaca-se, ainda, que foram pesquisados instituições e empreendimentos localizados em 11 municípios do Rio Grande do Sul, sendo eles: Ijuí, Cruz Alta, Santa Maria, Porto Alegre, Santana do Livramento, São Lourenço do Sul, Pelotas, Rio Grande, Santa Vitória do Palmar, Passo Fundo e São Leopoldo.

\footnotetext{
1 A nomenclatura das instituições de apoio e experiências coletivas pesquisadas foram substituídas por codificações, tendo como intencionalidade preservar a identificação no processo de análise das mesmas.
} 


\section{Percepções sobre a materialização do Programa de Economia Solidária em Desenvolvimento no Rio Grande do Sul}

O Programa de Economia Solidária em Desenvolvimento foi materializado e operacionalizado por meio de uma parceria estabelecida entre o governo federal - e outros setores governamentais -, incluindo as incubadoras universitárias, e, também pelas instituições da sociedade civil (BRASIL, 2011b). Algumas destas instituições, quando vinculadas ao estado, receberam apoio financeiro e de formação por meio de verbas advindas do governo federal, para desenvolver o trabalho de assessoria nas experiências coletivas.

Em relação ao levantamento realizado sobre as Instituições de Apoio vinculadas ao programa de Economia Solidária em Desenvolvimento no Rio Grande do Sul constatou-se que 20 instituições já tiveram ou possuíam algum vínculo com o Programa de Economia Solidária em Desenvolvimento entre 2003 a 2009 pela Senaes. As instituições de apoio eram o elo estabelecido entre o governo federal e os empreendimentos coletivos, pois obtinham recursos e aplicavam por meio de assessorias às experiências em seus territórios.

Destas 20 instituições averiguadas, 10 não possuíam convênio entre o período de 2008 e 2009 e 10 possuíam alguma forma de vínculo durante este período. Destas 20 instituições mapeadas, 11 participaram do estudo.

A vinculação do Programa de Economia Solidária em Desenvolvimento com as instituições de apoio ocorreu no estado via editais e chamadas públicas. Ou seja, as instituições de apoio elaboravam projetos sociais que visavam arrecadar recursos financeiros. A Senaes, juntamente com órgãos de fomento, abria editais e chamadas públicas, procurando formalizar a parceria entre o governo federal e as instituições de apoio, governamentais e da sociedade civil, incluindo as incubadoras universitárias. Os projetos selecionados e apoiados pela Senaes usufruíam de recursos públicos, bem como dos encontros de formação destinados às instituições, visando a capacitá-las. Constatou-se que há o processo de parceria estabelecida entre o estado e as instituições de apoio, e a forma existente de liberação de recursos (recursos esparsos, se equiparados à demanda, e com a forma de acesso, abertura de editais e elaboração, e aprovação de projetos sociais de extrema complexidade) no Rio Grande do Sul, e possivelmente no Brasil, mas estava ainda em fase inicial.

Destaca-se que esta realidade vinculada ao programa, em relação à liberação de recursos e as formas que são constituídas as parcerias com as instituições de apoio, poderia ter sido aprimorada. Cada estado e município poderiam ter tido setores específicos que 
dessem conta deste Programa, de forma que o mesmo correspondesse ao processo de descentralização político-administrativa. Outra questão importante está vinculada à materialização da transversalidade do programa com os outros programas e políticas sociais. Esta transversalidade, em algumas situações, necessitava também de abertura de editais, algo que poderia ser aprofundado e reformulado.

Apesar de suas limitações e incipiência do Programa verificou-se que das 20 instituições de apoio que possuíam ou tiveram alguma forma de vínculo com o Programa de Economia Solidária em Desenvolvimento por meio da Senaes, 40\% eram vinculadas à sociedade civil, $60 \%$ às instituições governamentais (sendo $20 \%$ incubadoras universitárias). Estas instituições supracitadas configuraram-se como o eixo de vinculação entre o governo federal e as experiências coletivas, mediante seus processos de assessoria e/ou incubação.

As instituições pesquisadas que iniciaram seu trabalho de assessoria posteriormente à criação da Senaes e do Programa de Economia Solidária eram atreladas, principalmente, aos setores governamentais. No estado estas instituições, incluindo os Centros Públicos, trabalhavam com as comunidades quilombolas e com o desenvolvimento de agentes de Economia Popular Solidária.

As Incubadoras Universitárias, vinculadas as instituições públicas, além de terem como intencionalidade aproximar a universidade da população local-regional e produzir conhecimentos de forma pró-ativa, objetivavam, também, assessorar os empreendimentos coletivos, visando contribuir para a viabilidade destes empreendimentos coletivos no mercado. A incubação além de capacitar e acompanhar os empreendimentos coletivos almejava também conseguir recursos por meio de elaboração de projetos e/ou parcerias estabelecidas com instituições públicas, privadas ou da sociedade civil.

O processo que envolve a metodologia de incubação normalmente empregada pelas instituições parceiras estava sendo realizado de forma que contemplasse as etapas relacionadas com os processos de pré-incubação, incubação e pós-incubação. Em relação ao processo de pós-incubação, o mesmo deve ser aprimorado. Este período constituiu-se segundo as informações levantadas no momento mais delicado do processo de assessoria. 0 tempo e os recursos previstos e destinados às instituições de apoio, quando contempladas por editais eram muito esparsos e descontínuos em relação à demanda necessária ao processo de pós-incubação, que poderia ter um maior acompanhamento. O próprio período de incubação já deveria ser prolongado devido a situação de vulnerabilidade social que estes 
trabalhadores se encontravam.

Os profissionais que respondiam administrativamente pelas instituições de apoio acabavam por se distanciar da realidade que envolve os trabalhadores assessorados. Este distanciamento, ocorrido em algumas situações, pode estar relacionado com o processo burocrático que estes profissionais estavam envoltos - no que concerne com a liberação de recursos e a manutenção do vínculo institucional com a Senaes, até para o próprio aprimoramento do programa.

Segundo as informações obtidas, as instituições pesquisadas vêm desenvolvendo as atividades de incubação e assessoria de forma que contemplassem os objetivos previstos pelo Programa e pela Senaes, como: a incubação e assessoria preparatória, a divulgação e promoção da Economia Popular Solidária, a formação e qualificação técnica, a preocupação com a comercialização dos produtos, entre outros. Salienta-se que estavam sendo desenvolvidas 6 atividades previstas pelo Programa Estadual: a) fomento e Assistência Técnica aos Empreendimentos Econômicos Solidários e Redes de Cooperação de Economia Solidária; b) cadastro de empreendimentos e entidades de apoio para manutenção e ampliação do Sistema de Informações em Economia Solidária; c) estímulo à institucionalização de Políticas Públicas de Economia Solidária; d) organização nacional da comercialização dos produtos e serviços de empreendimentos econômicos solidários; e) fomento à Incubadoras de Empreendimentos Econômicos Solidários; e f) promoção do Desenvolvimento Local e da Economia Solidária por meio da atuação de Agentes de Desenvolvimento Solidário. Predominavam, portanto, as atividades de Fomento e Assistência Técnica aos Empreendimentos Econômicos Solidários e Redes de Cooperação de Economia Solidária, seguidas pelo Cadastro de empreendimentos e entidades de apoio para manutenção e ampliação do SIES (2011).

Outra questão importante é que o Mapeamento de Economia Popular Solidária realizado pela Senaes consistiu na única ação concretizada por este programa social, mesmo com suas limitações e incipiência, em todos os estados brasileiros até o ano de 2009.

Em relação a percepção dos trabalhadores entrevistados no Rio Grande do Sul, 70,5\% informaram que o apoio e/ou o trabalho de assessoria/incubação desenvolvido pelas instituições, mesmo com limitações, contribuía para a viabilidade econômica e manutenção destes empreendimentos, de forma que possibilitasse a geração de renda aos trabalhadores por meio das atividades que estão realizando nestas experiências. Desta forma, pode-se 
constatar que no estado gaúcho as instituições de apoio contempladas vinham procurando desenvolver seus processos de assessoria e/ou incubação, tendo por objetivo contribuir principalmente para a viabilidade econômica das experiências de Economia Popular Solidária. Constatou-se, também, que o apoio governamental às experiências pesquisadas tornou-se fundamental para que as mesmas se mantivessem no mercado.

Outra atividade que era desenvolvida e que se destaca no estado, possuindo como característica o pioneirismo da "Instituição E", estava relacionada com a promoção das Feiras de Economia Popular Solidária. Estas são de extrema importância para o processo de comercialização dos produtos advindos destas experiências coletivas, como também para o fortalecimento da Economia Popular Solidária no Rio Grande do Sul e no Brasil - tanto em relação aos empreendimentos quanto ao fortalecimento e divulgação do supracitado Programa e de sua secretaria, para que futuramente, pudesse ter se criado uma política social pública destinada exclusivamente a este segmento social em âmbito nacional e as suas respectivas demandas.

Outra possibilidade, entretanto, pode consistir no fato de que este programa social pudesse ter sido incorporado pelo Ministério do Trabalho ou de Desenvolvimento Social, porém, de forma que fosse operacionalizado pela descentralização administrativa que envolve também as esferas governamentais estaduais e municipais. Ou seja, para se concretizar esta realidade, era necessária a criação e implantação nas prefeituras e estados, de uma secretaria, ou pelo menos de um setor responsável pelo desenvolvimento deste Programa Social. Assim como ocorre com outros programas e políticas, que também já percorreram uma trajetória de experiências, pressões sociais e reivindicações para que alcançassem esta realidade, mas ainda possuem limitações, pois o aprimoramento é processual.

Deste modo, constatou-se que no Rio Grande do Sul o Programa de Economia Solidária em Desenvolvimento foi elaborado ainda de maneira bem incipiente, seja pelas poucas quantidades de instituições vinculadas ao programa, pela forma de parceria estabelecida, pela maneira que o recurso financeiro foi gerido, liberado e aplicado e por meio das poucas atividades que estão previstas pelo Programa e pela Senaes que realmente puderam ser efetivadas no estado.

Por meio desta pesquisa pode-se averiguar, também, que as experiências pesquisadas estavam relacionadas com as cooperativas, associações e grupos informais que 
desenvolveram suas atividades nos meios urbanos e rurais em municípios do Rio Grande do Sul. Foram pesquisados 17 empreendimentos coletivos localizados nos meios urbanos em municípios do Rio Grande do Sul. No total foram realizadas 46 entrevistas, sendo 18 desenvolvidas com as lideranças dos empreendimentos coletivos e 28 com os outros trabalhadores inseridos nas experiências de Economia Popular Solidária.

Estes empreendimentos coletivos analisados possuíam as seguintes características: 2 empreendimentos se constituem enquanto cooperativas (11,7\%), 5 enquanto associações $(29,4 \%)$ e 10 enquanto grupos informais $(58,8 \%)$. Mediante estas informações, percebe-se que somente $41,1 \%$ das 17 experiências pesquisadas consistem em associações e cooperativas. Em relação aos 10 grupos pesquisados, constatou-se que 3 empreendimentos (30\%) estavam migrando da condição de grupos para associação.

A regulamentação e a legalização das experiências coletivas, que iniciam suas atividades por meio de grupos, constituíam-se em um dos objetivos do processo de assessoria e/ou incubação desenvolvido pelas instituições de apoio, bem como do Programa de Economia Solidária em Desenvolvimento e da Senaes, com a intenção de retirar estes grupos da extrema exclusão social.

Em relação às informações que dizem respeito aos trabalhadores inseridos nos 17 empreendimentos coletivos, apurou-se que predominam nas experiências pesquisadas a inserção de mulheres e que os fatores que contribuíram para a criação das experiências estão relacionados com uma alternativa ao desemprego para aumento e complemento da renda.

Destes 17 empreendimentos, $41,1 \%$ das experiências foram criadas pelos trabalhadores, $41,1 \%$ pelas instituições de apoio e $11,7 \%$ pelo governo do estado. Verificouse, também, que predominavam nestas experiências os trabalhos desenvolvidos com a reciclagem, gastronomia, produtos diversificados e confecção de roupas. Dos empreendimentos pesquisados identificou-se que somente 4 experiências (23,5\%) informaram que receberam alguma forma de apoio financeiro desde a sua criação, ou seja, recurso financeiro de algum órgão de apoio.

Em relação à viabilidade econômica, percebeu-se que os empreendimentos pesquisados sofrem concorrência de empresas, trabalhadores autônomos e atravessadores. Porém, mesmo assim, 88,2\% dessas entidades observadas conseguiam pagar suas despesas e ter alguma sobra. Novamente se destaca que o apoio governamental foi crucial para a viabilidade econômica e a manutenção destes empreendimentos coletivos. 
Considerando ainda o processo de trabalho, constatou-se: preocupação dos trabalhadores com este processo, direcionada à possibilidade de gerar trabalho e renda; preocupação com a possibilidade de integração entre os sujeitos durante a realização do trabalho, bem como com a comunidade local-regional; preocupação com o processo de qualificação dos sujeitos; preocupação com o desenvolvimento sustentável; preocupação com a valoração das periferias de forma que as mesmas passem a ser atendidas pelos governos municipais, que é mencionada pelo acesso às atividades assistenciais. Ou seja, a questão relacionada com a sobrevivência aparecia na preocupação central com a geração de renda e por meio das atividades assistenciais, materializada pelo acesso dos usuários a outros programas e benefícios sociais.

Em relação aos rendimentos individuais mensais adquiridos pelos trabalhadores pode-se identificar que: 2 empreendimentos obtinham geralmente uma renda de até 1 salário mínimo; os trabalhadores de 12 empreendimentos coletivos informaram que tinham uma renda mensal estabelecida entre 1 a 2 salários mínimos; os de outros 3 empreendimentos coletivos informaram que possuíam uma renda que oscilava entre 2 a 3 salários mínimos; e um empreendimento coletivo informou que possuía a renda de até 4 salários mínimos.

Ressalta-se ainda, que trabalhadores vinculados a 13 empreendimentos coletivos desenvolviam outras atividades para obter renda. Por meio destas informações constatou-se que a pobreza não pode ser caracterizada como algo "natural", mas sim como algo vinculado diretamente à questão social e ao processo das riquezas socialmente produzidas. Desta forma, averiguou-se a viabilidade econômica destes empreendimentos coletivos, mesmo que de forma não plena e sim limitada, devido aos baixos rendimentos atingidos.

Os trabalhadores pesquisados, em sua maioria, tiveram um aumento nas suas rendas após suas inserções nos empreendimentos coletivos, mesmo com os baixos rendimentos, fato que possibilitou uma melhoria nas suas condições de vida e, consequentemente de seus familiares. Outra questão relevante que caracterizava a situação de vulnerabilidade social destes sujeitos e a importância do Programa de Economia Solidária em Desenvolvimento, consistia no fato destes trabalhadores informarem que usufruíam também do Programa Bolsa-Família, entre outros benefícios. Assim, se constatou a transversalidade dos Programas e Políticas Sociais que é de fundamental importância para a melhoria das condições de vida destes sujeitos, retirando-os da condição de extrema pobreza.

Já em relação aos direitos trabalhistas destes sujeitos, certificou-se que dos 28 
trabalhadores que responderam estas questões, 18 não contribuíam para a Previdência Social e 10 contribuíam, porém, na condição de autônomos. Esta realidade é de extrema preocupação e importância, pois a maioria dos trabalhadores entrevistados, que possivelmente pode corresponder à totalidade dos sujeitos inseridos nestes tipos de experiências coletivas, não contribuía com a Previdência Social e estavam trabalhando na total informalidade, sem acesso aos direitos sociais, algo realmente preocupante.

Menciona-se 94,1\% das experiências participavam de instâncias que envolviam a sociedade civil organizada, em termos de Economia Popular Solidária, seja por meio de Fóruns, Feiras, encontros, entre outros. Verificou-se a participação da sociedade civil nas decisões e funções públicas, como forma de participação popular, fato este que ainda deve ser aprimorado no que se relaciona aos conselhos de direitos.

Ressalta-se que, primeiramente, os empreendimentos coletivos são criados para as necessidades vinculadas com a sobrevivência destes sujeitos, para, num segundo momento, serem dimensionados outros elementos relacionados com os Princípios da Economia Popular Solidária, como: aspectos sociais, políticos, educacionais, culturais, ambientais, entre outros. Pois constatou-se que o processo de conscientização e reflexão de suas ações e sobre a realidade social fazia parte do debate contido em 11 experiências coletivas pesquisadas.

Já em relação ao processo de gestão existente nas 17 experiências pesquisadas, depreendeu-se que 11 empreendimentos afirmaram possuir diretoria e 6 informaram que não possuem diretoria; 9 empreendimentos tinham todas as documentações necessárias para o funcionamento das cooperativas e associações; 4 empreendimentos possuíam parcialmente a documentação necessária para o funcionamento; e 4 não dispunham da documentação necessária para as suas regulamentações.

Nas 17 experiências de Economia Popular Solidária pesquisadas, identificou-se que todas desenvolviam reuniões e assembleias; $93,4 \%$ dos trabalhadores entrevistados responderam que tomavam parte das reuniões, assembleias e encontros e $95,4 \%$ dos sujeitos informaram que expunham suas opiniões quando não concordavam com algo ou alguma decisão, e que participavam das votações. Esta realidade demonstra um ensaio de novo patamar de politização e participação. Somente este processo de participação e conscientização, configuravam-se num grande avanço, se equiparado com a sociedade como um todo e o seu respectivo sistema econômico.

Os trabalhadores que informaram terem trabalhado em outros locais anteriormente, 
quando perguntados sobre se havia diferença entre ser empregado ou funcionário numa empresa privada e ser cooperado ou associado em uma experiência coletiva de geração de trabalho e renda: $83,3 \%$ responderam que existia esta diferença. É importante que se faça referência a essa realidade devido à possibilidade de ruptura que essas experiências coletivas, populares e solidárias introduziam nas relações que envolvem o processo de trabalho e gestão - respaldado em cooperação, rotatividade de atividades, democracia, participação, entre outros -, diferenciando-se, assim, na sua totalidade da lógica e da finalidade do sistema capitalista - individualidade, acumulação e centralização de capital. Outra questão relevante está vinculada à possível transformação na vida destes sujeitos que vivenciam o trabalho realizado nestas experiências coletivas.

Em relação às características dos trabalhadores, constatou-se que a maioria dos sujeitos está entre as faixas etárias de 31 a 40 anos (39,2\%), seguida pela de 51 a 60 (28,5\%). A metade dos trabalhadores possui Ensino Fundamental, 46,4\% Ensino Médio e apenas um trabalhador possui ensino superior.

Em relação aos motivos que desencadearam a inserção destes sujeitos nos empreendimentos coletivos, pode-se averiguar que 50\% foram pela necessidade de gerar e ter renda; $20 \%$ devido à influência e/ou convite de familiares; $20 \%$ para aumentar a renda familiar; e $10 \%$ informaram que era devido ao fato de que o trabalho desenvolvido em grupo era melhor, mais prazeroso. A maioria dos trabalhadores informou ainda que residiam com seus companheiros(as) e filhos possuindo casa própria. Constatou-se, desta forma, que os rendimentos obtidos pelos trabalhadores, além de serem destinados para as suas necessidades, também eram empregados para o complemento de suas rendas familiares.

Asseverou-se que, para que essas experiências pudessem ser mantidas e viabilizadas economicamente no mercado, era imprescindível o processo de comprometimento e o apoio/incentivo de políticas e programas sociais e de profissionais que os assessorassem pelo processo de incubação desenvolvido pelas instituições de apoio. Diante destas características, pode-se afirmar que as experiências coletivas assessoradas pelas instituições de apoio possuíam elementos em comum, como o fato de se constituírem em cooperativas, associações e grupos informais, que procuraram gerar trabalho e renda aos sujeitos pelos diversos ramos de atividades.

Enfatiza-se, entretanto, a importância que tinha o fortalecimento do Programa de Economia Solidária em Desenvolvimento e da Senaes, como forma de subsidiarem recursos 
financeiros e profissionais para assessorarem e qualificarem esses sujeitos, bem como os empreendimentos em que estão inclusos, tendo em vista o processo de descentralização político-administrativa (EID, 2004). Este apoio governamental, contudo, deveria ter como perspectiva a viabilidade econômica dos empreendimentos coletivos, e não a dependência e/ou terceirização dos serviços públicos e privados.

Menciona-se, ainda, que 6 experiências coletivas tinham dificuldades vinculadas às relações que eram estabelecidas pelos trabalhadores diante do processo de gestão e produção, entre outras divergências. Estes 6 empreendimentos possivelmente não desenvolviam suas atividades de acordo com os princípios da "Economia Popular Solidária". Os outros 11 empreendimentos - apesar de limitações e conflitos -, constituíam-se por meio de elementos que pudessem ser remetidos à Economia Popular Solidária, sem desconsiderar as contradições internas e externas na qual estas experiências estavam inseridas.

\section{Ponderações Finais}

Inferiu-se que o Programa de Economia Solidária em Desenvolvimento, mesmo com suas limitações e incipiências, pela parceria estabelecida entre o estado e as instituições de apoio contribuíam para a viabilidade econômica, entre outros aspectos, de forma fundamental para estas experiências coletivas, mesmo quando eram poucos os rendimentos obtidos pelos trabalhadores (entre meio salário mínimo a 4 salários mínimos), pois pode-se constatar que estes eram muito significativos a estes sujeitos e seus familiares.

O governo estadual, por meio do Programa de Economia Solidária em Desenvolvimento, vinculado à Senaes, juntamente com as incubadoras universitárias e demais instituições governamentais e com as da sociedade civil, desde que em parceria com o governo federal, potencializavam e viabilizavam as experiências de Economia Popular Solidária, mesmo que ainda de forma incipiente. Salienta-se esta realidade sem desconsiderar a categoria de contradição que permeia estes empreendimentos coletivos e seu respectivo Programa Social.

Salienta-se esta possibilidade, principalmente, diante da atual realidade que envolve o mercado de trabalho, pois este Programa contribuiu para a geração de renda dos trabalhadores e suas respectivas famílias no Rio Grande do Sul, afastando-os da condição de extrema pobreza.

Diante desta realidade, menciona-se que o aprimoramento do Programa era algo 
processual e contínuo, pois estava em fase de "Desenvolvimento", de modo que as pesquisas científicas sobre o mesmo buscam contribuir com o aprimoramento do mesmo. Assim, este programa configurou-se como uma forma de geração de renda do que um meio de contestação ao sistema, realidade que se configura, apesar da sua importância, como funcional ao sistema.

Com a inserção da classe trabalhadora na lógica do sistema, em que é considerado cidadão, o sujeito que está incluído no mercado formal de trabalho ou que possui uma fonte de renda, enfatiza-se que para este tipo de empreendimento o apoio governamental era fundamental frente à profundidade da desigualdade brasileira. Esses empreendimentos coletivos geralmente eram suscitados pelos sujeitos e instituições de apoio diante das manifestações de desigualdade da questão social: matéria-prima de trabalho dos assistentes sociais.

Contraditoriamente, estes empreendimentos e seu respectivo programa social, podem ser considerados estratégias do próprio sistema e do Estado, para atenuar os conflitos de classe, mantendo e reproduzindo também o status quo. Outras formas de precarização do trabalho e regulação da questão social podem ser tidas pelo trabalho temporário, informal, terceirizado, entre outros. Ao estarem exclusos do mercado formal de trabalho, os trabalhadores (as) também estão inseridos na lógica do sistema capitalista, pois o desemprego é inerente a este modo de produção.

A exclusão na produção de bens e serviços ocorre também por meio da inclusão no sistema, sendo que a exclusão, além de necessária ao capitalismo, também se configura como uma modalidade de inserção que se define paradoxalmente pela não participação e pelo não acesso à riqueza socialmente produzida (YAZBEK, 2001). Desta forma, ao mesmo tempo em que comumente os trabalhadores das experiências de Economia Popular Solidária estão exclusos do mercado formal de trabalho, os mesmos porém, estão incluídos no sistema em condição de vulnerabilidade social.

O Programa de Economia Solidária em Desenvolvimento e a Senaes, entretanto, possuíam relevância, devido ao fato de terem como intencionalidade contribuir para a viabilidade econômica e manutenção das experiências coletivas, que se constituem como uma das alternativas existentes para a geração de trabalho e renda no Brasil diante do desemprego, principalmente aos sujeitos que comumente estão em situação de vulnerabilidade social e, consequentemente de seus familiares. 


\section{Referências}

BARDIN, Laurence. Análise de conteúdo. 6. ed. São Paulo: Amedina, 2011.

BRASIL. Ministério do Trabalho e Emprego. Organização nacional da comercialização dos produtos e serviços de empreendimentos econômico solidário. Disponível em: http://www.mte.gov.br/ ecosolidaria/prog_organizacao.asp. Acesso em: 4 mar. 2011a.

BRASIL. Ministério do Trabalho e Emprego. Programa economia solidária em desenvolvimento. Disponível em: http://www.mte.gov.br/ecosolidaria/prog_default.asp. Acesso em: 2 mar. 2011c. era 2011b.

ECONOMIA solidária. Mapeamento Rio Grande do Sul. Brasília: Impressão AMBP, 2007.

EID, Farid. Análise sobre processos de formação de incubadoras universitárias da Unitrabalho e metodologia de incubação de EES. In: PICANÇO, Iraci; TIRIBA, Lia (org.). Trabalho e educação. Aparecida, SP: Ideias \& Letras, 2004. p. 167-188.

LEBOUTTE, Paulo. Economia popular solidária e políticas públicas: a experiência pioneira do Rio Grande do Sul: ITCP; Rio de Janeiro: COPPE, 2003.

SIES. Sistema Nacional de Informações em Economia Solidária. Economia Solidária. Mapeamento Rio Grande do Sul. Impressão: AMBP - Sociedade Banco de Projetos. A publicação deste caderno, "Economia Solidária - Mapeamento Rio Grande do Sul" é resultado do mapeamento nacional realizado pela Secretaria Nacional de Economia Solidária (Senaes/MTE), em Convênio firmado entre Unitrabalho e Finep, Ref: 2297/06 - no 01.06.0547.00, 2007

SINGER, Paul. Economia socialista. In: SINGER, Paul; MACHADO, João (org.). Economia socialista. São Paulo: Fundação Perseu Abramo, 2000.

YAZBEK, Maria Carmelita. Pobreza e exclusão social: expressões da questão social no Brasil. Temporalis, São Paulo, v. 3, p. 33-40, 2001. 